\title{
Facile Synthesis of Rambutan-Like ZnO Hierarchical Hollow Microspheres with Highly Photocatalytic Activity
}

\author{
Ke-Jian Ju, ${ }^{1}$ Ming Zhang, ${ }^{2}$ Qian-Li Zhang, ${ }^{1}$ Jie Wei, ${ }^{1}$ and Ai-Jun Wang ${ }^{2,3}$ \\ ${ }^{1}$ School of Chemistry and Biological Engineering, Suzhou University of Science and Technology, Suzhou 215009, China \\ ${ }^{2}$ School of Chemistry and Chemical Engineering, Henan Normal University, Xinxiang 453007, China \\ ${ }^{3}$ College of Geography and Environmental Science, Zhejiang Normal University, Jinhua 321004, China
}

Correspondence should be addressed to Qian-Li Zhang; zqlmhb@163.com and Ai-Jun Wang; ajwang@zjnu.cn

Received 11 February 2015; Accepted 17 March 2015

Academic Editor: Aiping Chen

Copyright (C) $2015 \mathrm{Ke}$-Jian Ju et al. This is an open access article distributed under the Creative Commons Attribution License, which permits unrestricted use, distribution, and reproduction in any medium, provided the original work is properly cited.

\begin{abstract}
Rambutan-like $\mathrm{ZnO}$ hierarchical hollow microspheres ( $\mathrm{ZnO} \mathrm{HHMs}$ ) were constructed under hydrothermal conditions, using carboxyl methyl starch (CMS) as a soft template. The resulting products were characterized by using X-ray diffraction (XRD), scanning electron microscopy (SEM), and transmission electron microscopy (TEM). The experimental parameters and growth mechanism of rambutan-like $\mathrm{ZnO} \mathrm{HHMs}$ were discussed in some detail. The as-prepared samples displayed improved photocatalytic activity for the degradation of rhodamine B under ultraviolet (UV) irradiation.
\end{abstract}

\section{Introduction}

$\mathrm{ZnO}$ has attracted global interest as a promising alternative semiconductor to $\mathrm{TiO}_{2}$ in dye-sensitized solar cells, owing to its direct wide band gap $(3.37 \mathrm{eV})$ and high electron mobility $\left(17 \mathrm{~cm}^{2} \cdot \mathrm{V}^{-1} \cdot \mathrm{s}^{-1}\right)$ for single-crystal $\mathrm{ZnO}$ nanostructures $[1,2]$. Furthermore, single-crystalline $\mathrm{ZnO}$ displays efficient electron transport collection and a faster charge transfer for its $2 / 3$-fold electron mobility than $\mathrm{TiO}_{2}$. As a result, singlecrystalline $\mathrm{ZnO}$ with a variety of sizes and shapes have been prepared, including nanowires [3, 4], nanofiber [5], nanodiscs $[6]$, nanorods $[7,8]$, nanotubes $[9,10]$, nanonails [11], coreshell [12], and hierarchical structures [13, 14].

Now, one-dimensional (1D) $\mathrm{ZnO}$ nanostructures such as nanowires and nanotubes have been prepared to reduce recombination phenomena upon the electron transport process and improve the electron collection efficiency [15]. However, these 1D structures suffer from a rather low specific surface area. To solve this issue, $\mathrm{ZnO}$ hollow structures have attracted great attention because of their huge active surface area, stability, high porosity, and permeability (mesoporous nature) $[16,17]$.

To date, hollow $\mathrm{ZnO}$ spheres have mainly been synthesized by hard template [18]. For instance, $\mathrm{ZnO}$ hollow spheres have been prepared using spherobacterium Streptococcus thermophilus as a biotemplate [19]. However, the incubation of bacteria is time-consuming and complicated and requires special agents. Furthermore, expensive raw materials, complex process control, and sophisticated equipment are often needed, which is unfavorable for potential large-scale synthesis of single-crystal $\mathrm{ZnO}$ structures.

Alternatively, soft templates are expected to be more flexible in preparing $\mathrm{ZnO}$ hollow structures. For example, hierarchically nanoporous $\mathrm{ZnO}$ hollow spheres were facilely obtained using glucose as a template [20], where calcining the products is essential. Lately, flower-like and double-caged peanut-like $\mathrm{ZnO}$ hollow structures were prepared in our group [21, 22], which showed enhanced surface area and improved catalytic activity. Moreover, hollow microsphere assembled by the units (e.g., nanoparticles and nanorods) have some additional advantages such as enlarged surface area, easy separation, rich interface, and good stability [2022].

Hydrothermal method is usually used for the synthesis of high-crystallized powders, owing to its simplicity, facility, low cost, and scalability $[23,24]$. Besides, the products will own high purity and narrow particle size distribution. Herein, a simple hydrothermal method was developed for large-scale 
synthesis of rambutan-like $\mathrm{ZnO}$ hierarchical hollow microspheres (HHMs) under low temperature $\left(120^{\circ} \mathrm{C}\right)$ without the calcination procedure, using carboxyl methyl starch (CMS) as a soft template. The catalytic activity of the resulting product was examined by the photodegradation of rhodamine $\mathrm{B}$ as a model system.

\section{Experimental Section}

2.1. Chemical and Reagents. All the reagents were of analytical grade and were purchased from Aladdin Industrial Corporation and used without further purification. All aqueous solutions were prepared with twice-distilled water.

2.2. Preparation of Rambutan-Like ZnO HHMs. The rambutan-like $\mathrm{ZnO}$ HHMs were prepared with the assistance of CMS under hydrothermal conditions. In a typical procedure, $0.65 \mathrm{~g}$ of CMS was dissolved in $25 \mathrm{~mL}$ of water under stirring, followed by the addition of $6.25 \mathrm{~mL}$ of zinc nitrate solution $(50 \mathrm{mM})$ into the above solution under stirring. Next, $0.625 \mathrm{~mL}$ of ammonia solution $(25 \%, w / V)$ was dropwise put into the mixed solution. After stirring for $15 \mathrm{~min}$, the mixture was transferred to a $50 \mathrm{~mL}$ Teflon-lined autoclave, sealed, and kept at $120^{\circ} \mathrm{C}$ for $12 \mathrm{~h}$ and finally cooled to room temperature naturally. The final white precipitate was collected by centrifugation, thoroughly washed with water and ethanol, and dried at $60^{\circ} \mathrm{C}$ in vacuum.

Control experiments with different amounts of ammonia and CMS and different temperature were performed, respectively. And the time-dependent experiments were conducted to investigate the formation mechanism of rambutan-like $\mathrm{ZnO}$ HHMs.

2.3. Characterization. Field emission scanning electron microscopy (FESEM) was performed with a JSM-6390LV microscope. Transmission electron microscope (TEM) and high-resolution TEM (HRTEM) images were recorded on a JEOL JEM-2100F using an accelerating voltage of $200 \mathrm{kV}$. $\mathrm{X}$-ray diffraction (XRD) analysis was carried out on a Rigaku Dmax-2000 diffractometer with $\mathrm{Cu} K \alpha$ radiation. The surface areas were calculated by the Brunauer-Emmett-Teller (BET) method, and the pore size distribution was calculated from the adsorption branch using the Barett-Joyner-Halenda $(\mathrm{BJH})$ theory. The UV-vis spectra were recorded on a Lambda $950 \mathrm{UV} /$ vis spectrometer (PerkinElmer, USA).

2.4. Photocatalytic Experiments. The photocatalytic activity of the samples was evaluated by the photocatalytic decolorization of rhodamine $\mathrm{B}$ ( $\mathrm{RhB}$, Amresco Inc.) in aqueous solution at ambient temperature. To improve the degree of crystallinity, the product was calcined at $400^{\circ} \mathrm{C}$ for $2 \mathrm{~h}$. Photocatalytic experiments were performed as follows: the reaction system containing $50 \mathrm{~mL}$ of $\mathrm{RhB}$ with an initial concentration of $2.5 \times 10^{-5} \mathrm{M}$ and $15 \mathrm{mg}$ of the $\mathrm{ZnO}$ samples was stirred in the dark for $1 \mathrm{~h}$ to reach adsorption-desorption equilibrium before ultraviolet (UV) light irradiation. A $300 \mathrm{~W}$ highpressure Hg lamp (Yaming Company, Shanghai, $8 \mathrm{~cm}$ away from the suspension) was used as a light source to trigger the photocatalytic reaction. The solutions were collected and centrifuged every 10 min to measure the degradation of $\mathrm{RhB}$ in solution by UV-vis spectroscopy.

\section{Results and Discussion}

3.1. Characterization of Rambutan-Like $\mathrm{ZnO} H H M s$. Figure 1(a) shows the typical SEM image of rambutan-like $\mathrm{ZnO} \mathrm{HHMs}$ with the average diameter of $\sim 1 \mu \mathrm{m}$, where $\mathrm{ZnO}$ nanorods perpendicularly grow outwards on the surface of the shell, regardless of the curvature of $\mathrm{ZnO}$ microspheres (Figures 1(a)-1(c)). This observation is different from that of commercial $\mathrm{ZnO}$ samples with irregular nanoparticles (Figures S1 and S2A in Supplementary Material available online at http://dx.doi.org/10.1155/2015/242798, supporting information). Higher magnification SEM image of the cracked one demonstrates their hollow spheres again (Figure 1(c)).

As illustrated by the XRD pattern of typical ZnO HHMs (Figure $1(\mathrm{~d})$ ), all the diffraction peaks are well indexed to the wurtzite hexagonal $\mathrm{ZnO}$ with lattice constants $a=$ $3.249 \AA$ and $c=5.207 \AA$ (JCPDS card 36-1451) [25, 26], respectively. No any other peaks from impurity are observed, revealing complete removal of the soft template in our system, as further proved by FTIR analysis (Figure S3, supporting information) in which all the characteristic peaks match well with pure $\mathrm{ZnO}$ nanoparticles [27].

TEM measurements were conducted to provide more detailed information about $\mathrm{ZnO}$ HHMs (Figure 2). Notably, the slight pale center together with the deep dark edge outside evidences the sphere with a large void space inside (Figure 2(a)). Similar spheres were observed using polystyrene microspheres as a hard template [28], while solid spheres were obtained with larger sizes $(5 \mu \mathrm{m})$ in their system. The selected area electron diffraction (SAED) patterns taken from the selected area of the TEM image (Figure 2(b)) show their single-crystalline nature. Additionally, Figures 2(c)-2(d) show that all parts of the nanorods on the $\mathrm{ZnO}$ spheres surface only have the fringes of planes with $d$ value of $0.25 \mathrm{~nm}[29]$, suggesting that the nanorods exhibit the $\{10 \overline{1} 1\}$ orientation. The commercial $\mathrm{ZnO}$ samples are also highly crystalline with a plane spacing of $0.26 \mathrm{~nm}$, corresponding to the distance between two (0002) crystal planes, which indicates that they preferentially grow along the [0001] directions [29] (Figure S2B, supporting information).

Figure 3 provides the nitrogen adsorption-desorption isotherm of the typical sample calcined at $300^{\circ} \mathrm{C}$. The isotherm displays a typical IV curve, while the hysteresis loop is associated with narrow slit-like pores in the sample, as confirmed by the pore size distribution curve (Inset in Figure 3). The BET specific surface area of the product is about $41.5 \mathrm{~m}^{2} \cdot \mathrm{g}^{-1}$, which is much larger than that of commercial $\mathrm{ZnO}$ powders with a value of $3.64 \mathrm{~m}^{2} \cdot \mathrm{g}^{-1}$ [30]. This value is also higher than those of $\mathrm{ZnO}$ hollow spheres with the value of $9.77 \mathrm{~m}^{2} \cdot \mathrm{g}^{-1}$ [30] and $\mathrm{ZnO}$ flowers with the value of $25.16 \mathrm{~m}^{2} \cdot \mathrm{g}^{-1}$ [31]. The corresponding pore size distribution curve exhibits that most of the pores have the size of $c a .20 \mathrm{~nm}$. The enlarged surface area of $\mathrm{ZnO}$ HHMs is expected to have excellent photocatalytic performance. 


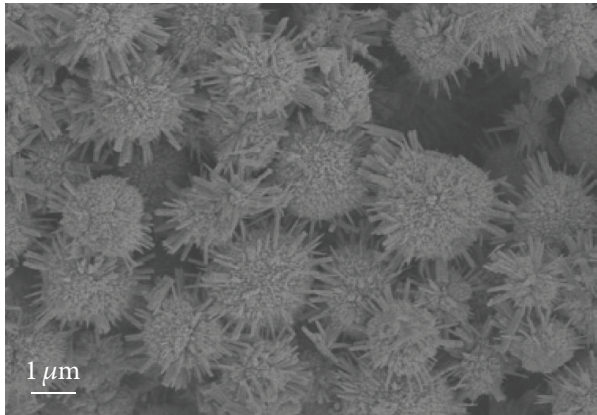

(a)

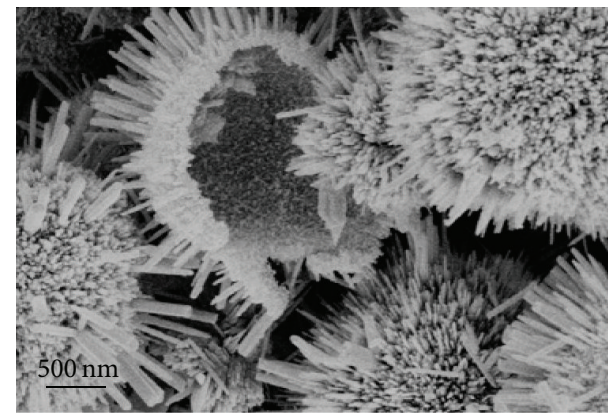

(c)

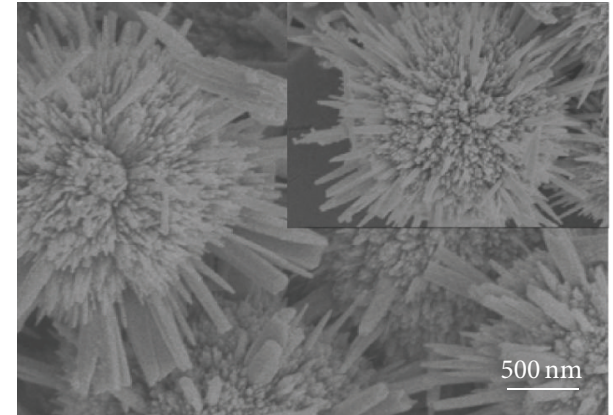

(b)

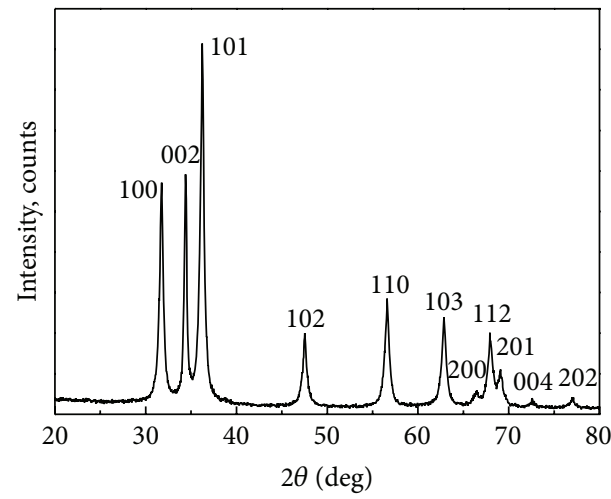

(d)

Figure 1: Morphological and structural characterizations of rambutan-like ZnO HHMs: the corresponding low (a) and high ((b)-(c)) magnification of the SEM images and the XRD patterns (d). The inset shows the high magnification of the SEM images of (b).
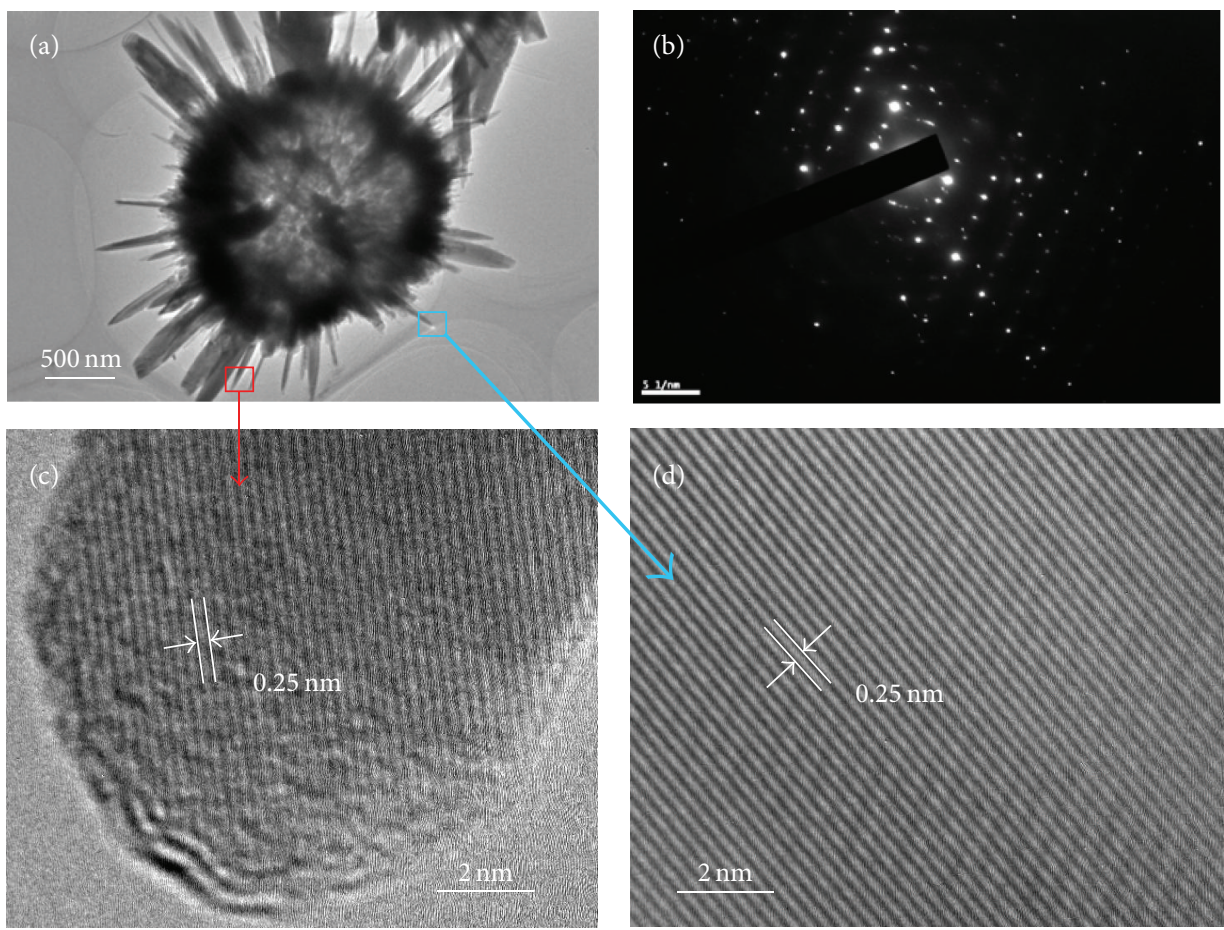

FIgURE 2: (a) TEM image of rambutan-like ZnO HHMs. (b) The SAED patterns corresponding to the selected area of the TEM image. HRTEM images of the tip (c) and the main body (d) of the nanorods on the hollow sphere. 


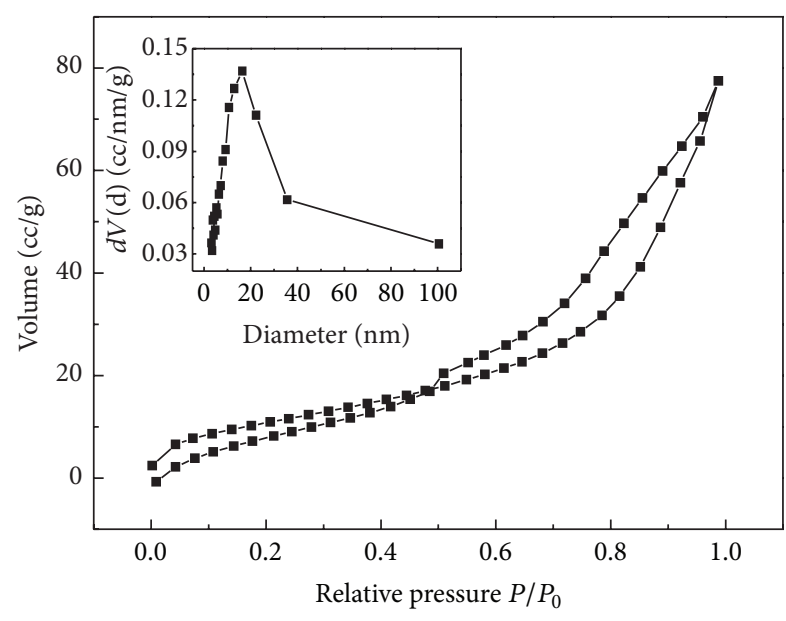

Figure 3: Typical $\mathrm{N}_{2}$ gas adsorption-desorption isotherm of rambutan-like $\mathrm{ZnO} \mathrm{HHMs}$. Inset shows the corresponding pore size distribution.

3.2. Effects of Ammonia. The amount of ammonia is crucial for the formation of unique rambutan-like $\mathrm{ZnO} \mathrm{HHMs}$ (Figure 4). When $0.3 \mathrm{~mL}$ ammonia is put into the reaction system, $\mathrm{ZnO}$ spheres are basically formed with rough surface (Figure 4(a)), while some $\mathrm{ZnO}$ spheres were obtained with a few nanorods on the surface (Figure 4(b)) by using $0.5 \mathrm{~mL}$ ammonia. However, the density of the nanorods decreases on the spheres in the case of $0.7 \mathrm{~mL}$ ammonia (Figure 4(c)), and bald $\mathrm{ZnO}$ particles emerge by the addition of $1.2 \mathrm{~mL}$ ammonia to the reaction system (Figure $4(\mathrm{~d})$ ).

3.3. Effects of CMS. CMS is served as prior nucleation sites for $\mathrm{ZnO}$ at the initial crystallization process. When the CMS concentration is low $\left(2 \mathrm{mg} \cdot \mathrm{mL}^{-1}\right)$, there are a lot of bare $\mathrm{ZnO}$ spheres with rough surfaces (Figure 5(a)). And vertical $\mathrm{ZnO}$ nanorods grow on the $\mathrm{ZnO}$ spheres in the presence of $2.6 \mathrm{mg} \cdot \mathrm{mL}^{-1} \mathrm{CMS}$, resulting in rambutan-like morphology (Figure 1(a)). However, sufficient CMS such as $4 \mathrm{mg} \cdot \mathrm{mL}^{-1}$ would prevent the growth of nanorods on the surface of $\mathrm{ZnO}$ hollow spheres, causing the lower density of the nanorods (Figure 5(b)). Besides, $6 \mathrm{mg} \cdot \mathrm{mL}^{-1} \mathrm{CMS}$ induces the emergence of many deformed and even broken $\mathrm{ZnO}$ flowers (Figure 5(c)), because the nucleation takes place along the prior nucleation sites. When the amount of CMS further increased to $12 \mathrm{mg} \cdot \mathrm{mL}^{-1}$ (Figure $5(\mathrm{~d})$ ), disordered aggregates are formed.

3.4. Effects of the Reaction Temperature. Different morphologies are obtained by adjusting the reaction temperature from 80 to $160^{\circ} \mathrm{C}$. The aggregation of $\mathrm{ZnO}$ spheres (Figure 6(a)) transforms to immature rambutan-like crystals below $100^{\circ} \mathrm{C}$ (Figure 6(b)), and well-defined rambutan-like $\mathrm{ZnO} \mathrm{HHMs}$ were obtained at $120^{\circ} \mathrm{C}$ (Figure 2(b)). However, the density of the nanorods on the surfaces of $\mathrm{ZnO}$ HHMs drops down at $140^{\circ} \mathrm{C}$ (Figure 6(c)), and broken bald spheres show up as the temperature is up to $160^{\circ} \mathrm{C}$ (Figure $6(\mathrm{~d})$ ). These results demonstrate that the rates of the nucleation and crystal growth are sensitive to the reaction temperature [22]. At lower temperature, the crystal growth rate is higher than that of nucleation. The increase of the temperature greatly facilitates the nucleation rate and the newly generated crystal nuclei are easy to aggregate together, realizing crystal growth for adequate space present, leading to the formation of rambutan-like $\mathrm{ZnO}$ HHMs. On the contrary, at much higher temperature, the nucleation rate is much higher than that of crystal grain growth, and thereby crystal nuclei are produced.

\subsection{Effects of the Reaction Time and Formation Mechanism.} Time-dependent experiments were carried out to deeply understand the formation mechanism of $\mathrm{ZnO}$ HHMs (Figures $7(\mathrm{a})-7(\mathrm{~d}))$. Firstly, the products are just composed of solid spheres with the reaction time of $2 \mathrm{~h}$ (Figure $7(\mathrm{a})$ ). When the reaction time is $5 \mathrm{~h}$, small nanorods emerge on $\mathrm{ZnO}$ spheres (Figure 7(b)) and rambutan-like $\mathrm{ZnO}$ HHMs as the reaction time is $12 \mathrm{~h}$ (Figure $2(\mathrm{~b})$ ). However, the density of the nanorods is decreased by extending the reaction time to 24 (Figure 7(c)) and $48 \mathrm{~h}$ (Figure 7(d)), owing to the Ostwald ripening effects (Figure 8).

In general, $\mathrm{ZnO}$ has a strong tendency to self-oriented growth. At the initial stage, newly generated $\mathrm{ZnO}$ is quickly congregated to spherical aggregates to decrease their surface energies and hence amorphous solid spheres are formed through the following reactions $[21,32]$ :

$$
\begin{gathered}
\mathrm{NH}_{3}+\mathrm{H}_{2} \mathrm{O} \Longleftrightarrow \mathrm{NH}_{3} \cdot \mathrm{H}_{2} \mathrm{O} \Longleftrightarrow \mathrm{NH}_{4}{ }^{+}+\mathrm{OH}^{-} \\
\mathrm{Zn}(\mathrm{OH})_{4}{ }^{2-} \stackrel{4 \mathrm{OH}^{-}}{\longleftarrow} \mathrm{Zn}^{2+} \stackrel{4 \mathrm{NH}_{3}}{\longrightarrow} \mathrm{Zn}\left(\mathrm{NH}_{3}\right)_{4}{ }^{2+} \\
\mathrm{Zn}(\mathrm{OH})_{4}{ }^{2-} \longrightarrow \mathrm{ZnO}+\mathrm{H}_{2} \mathrm{O}+2 \mathrm{OH}^{-} \\
\mathrm{Zn}\left(\mathrm{NH}_{3}\right)_{4}{ }^{2+}+2 \mathrm{OH}^{-} \longrightarrow \mathrm{ZnO}+4 \mathrm{NH}_{3}+\mathrm{H}_{2} \mathrm{O}
\end{gathered}
$$

It should be mentioned that the original solid phase might not be well crystallized, owing to rapid spontaneous nucleation. Thus, Ostwald ripening dictates growth and recrystallization after hydrolysis. With time extending, the surface layer of the spheres firstly crystallizes, due to the direct contact with the surrounding solution. As a result, the materials inside the solid spheres have a strong tendency to dissolve, which provides the driving force for the spontaneous Ostwald ripening [33]. This assumption is strongly supported by the above experimental data, while it is different from that described by Shen's group [34]. In their work, original solid microspheres were composed by $\mathrm{Zn}(\mathrm{OH})_{2}$, rather than solid $\mathrm{ZnO}$ spheres in our case (Figure S4, supporting information).

The formation process of rambutan-like $\mathrm{ZnO}$ HHMs can be further addressed by TEM measurements (Figure 9). At the very early stage, the precipitated crystallites assemble together to form solid $\mathrm{ZnO}$ spheres (Figures 9(a) and 9(b)). With the increase of the reaction time, the inner crystallites with higher surface energy would dissolve and transfer outside to produce channels connecting inner and outer spaces in the oxide shells (Figure 9(c)) [35]. Finally, the hollow interior of the $\mathrm{ZnO}$ spheres emerged (Figure 9(d)), which is also supported by the broken one from the SEM image (Figure 1(c)). 


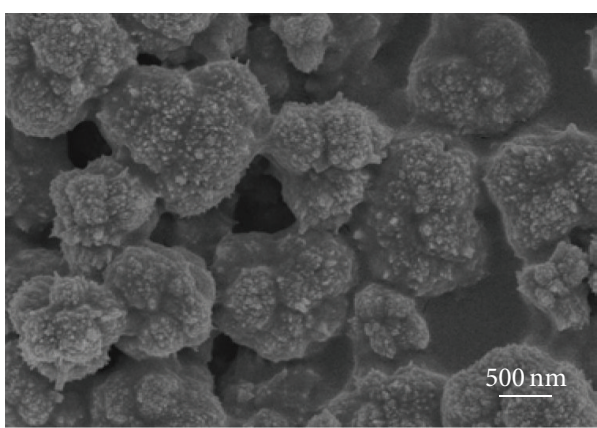

(a)

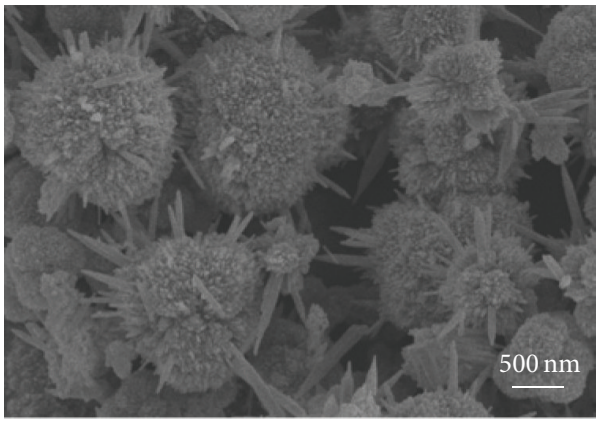

(c)

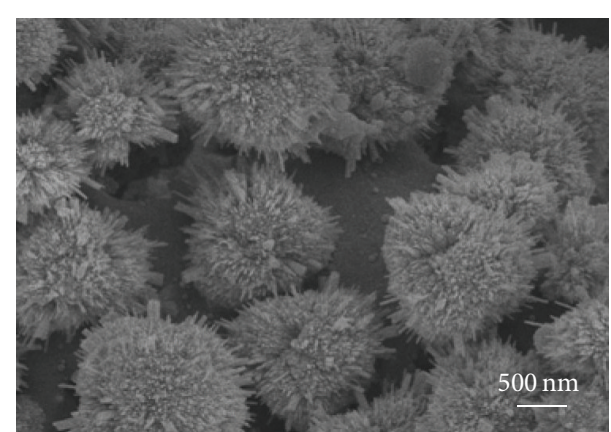

(b)

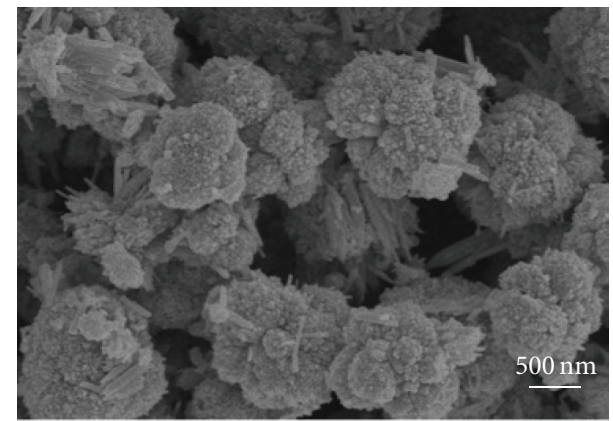

(d)

FIGURE 4: SEM images of the products prepared with different volumes of ammonia: $0.3 \mathrm{~mL}(\mathrm{a}), 0.5 \mathrm{~mL}$ (b), $0.7 \mathrm{~mL}$ (c), and $1.2 \mathrm{~mL}$ (d).

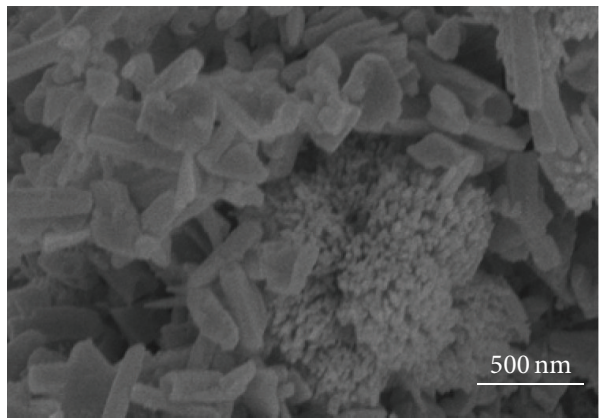

(a)

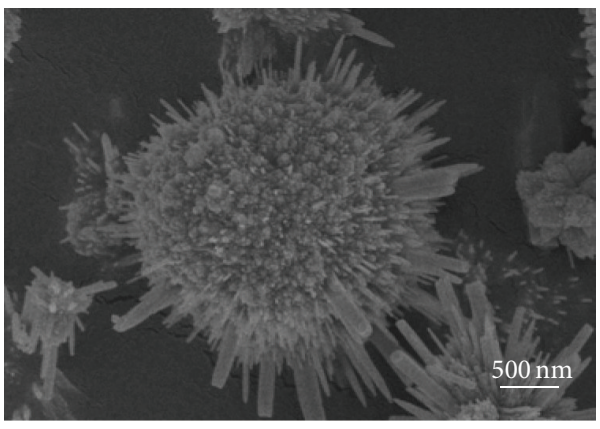

(c)

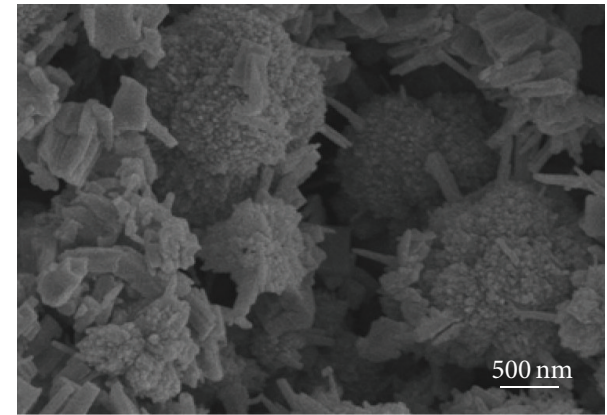

(b)

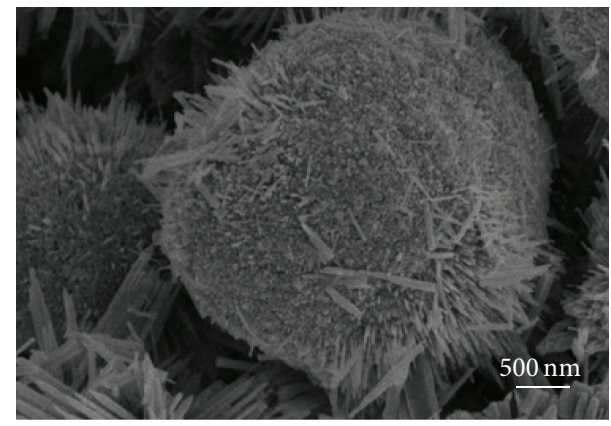

(d)

FIGURE 5: SEM images of the products prepared with different amounts of CMS: $2 \mathrm{mg} \cdot \mathrm{mL}^{-1}$ (a), $4 \mathrm{mg} \cdot \mathrm{mL}^{-1}$ (b), $6 \mathrm{mg} \cdot \mathrm{mL}^{-1}(\mathrm{c})$, and $12 \mathrm{mg} \cdot \mathrm{mL}^{-1}$ (d). 


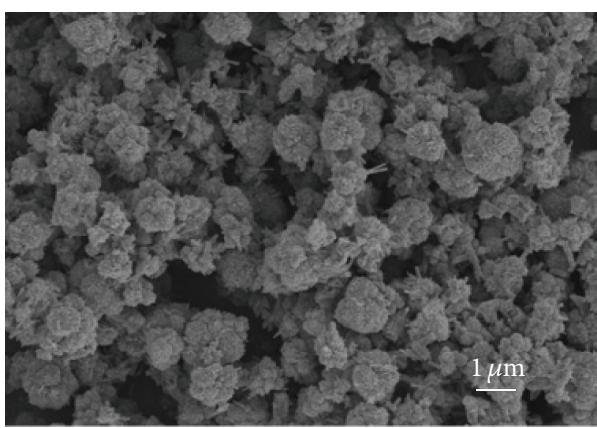

(a)

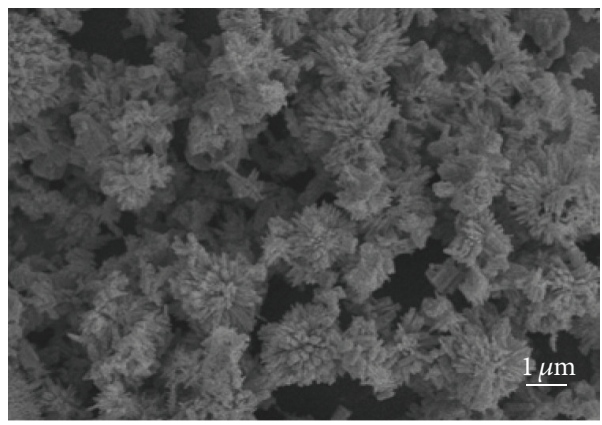

(c)

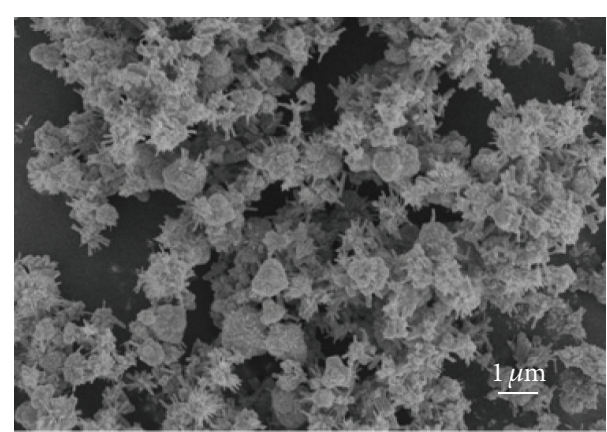

(b)

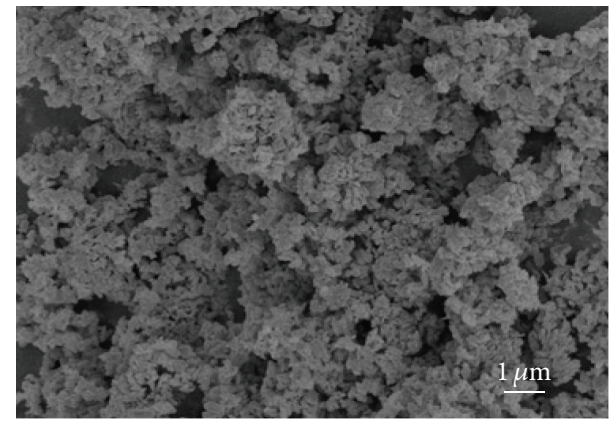

(d)

FIgURE 6: SEM images of the products obtained at different reaction temperature: $80^{\circ} \mathrm{C}(\mathrm{a}), 100^{\circ} \mathrm{C}(\mathrm{b}), 140^{\circ} \mathrm{C}(\mathrm{c})$, and $160^{\circ} \mathrm{C}(\mathrm{d})$.

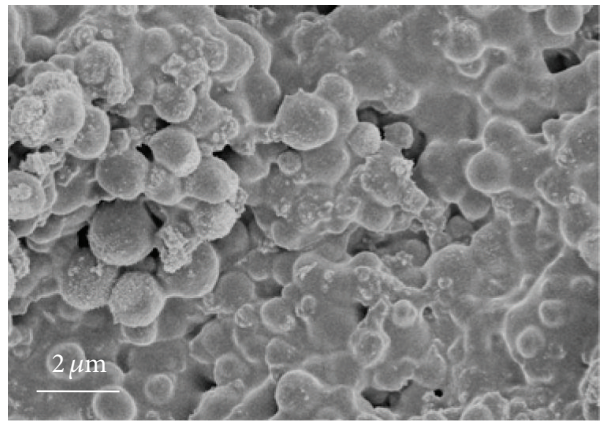

(a)

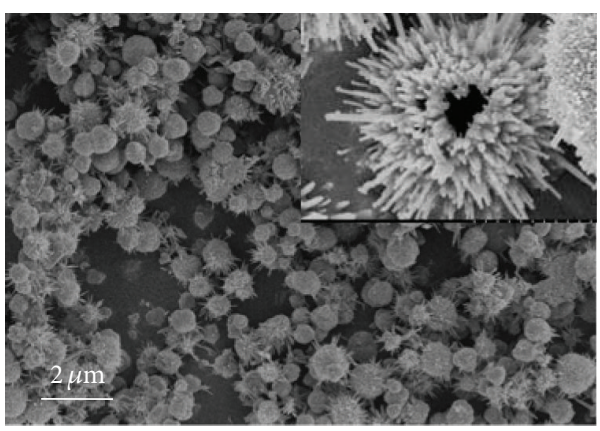

(c)

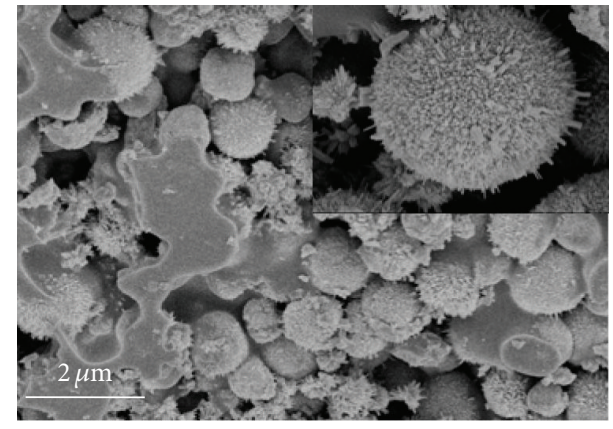

(b)

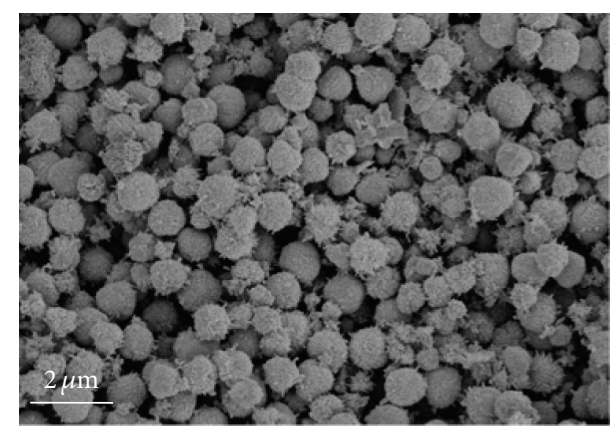

(d)

FIGURE 7: SEM images of the products obtained at different reaction time: $2 \mathrm{~h} \mathrm{(a),} 5 \mathrm{~h}$ (b), $24 \mathrm{~h}$ (c), and $48 \mathrm{~h}$ (d). Inset shows high magnification of the images (b) and (c). 


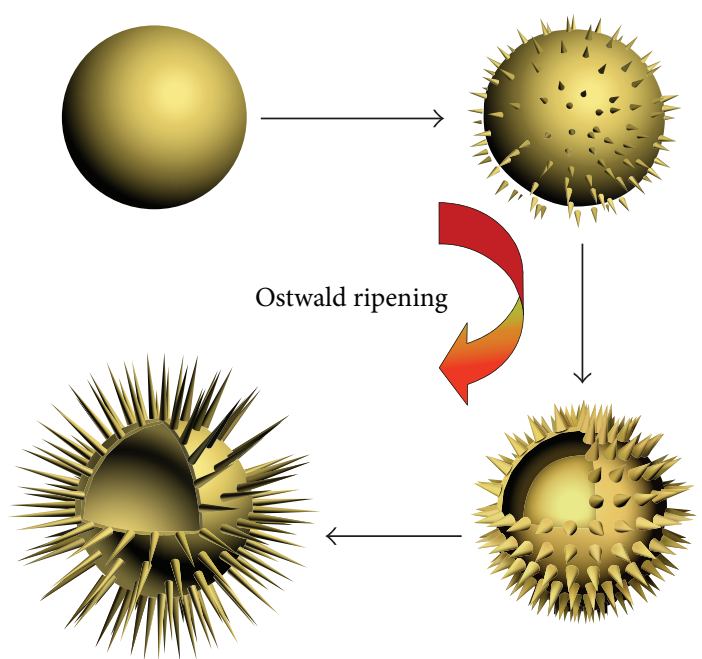

Figure 8: The formation mechanism of rambutan-like $\mathrm{ZnO}$ HHMs based on time-dependent evolution of the growth process.

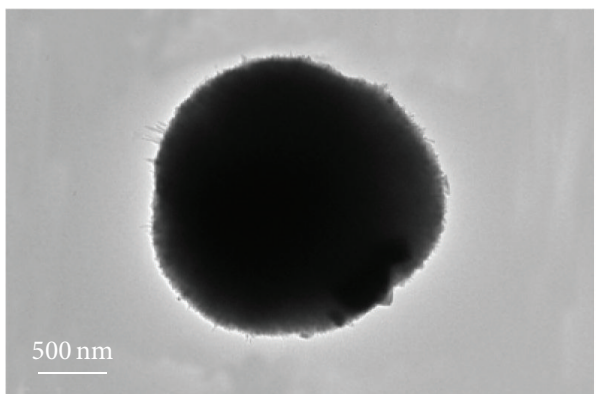

(a)

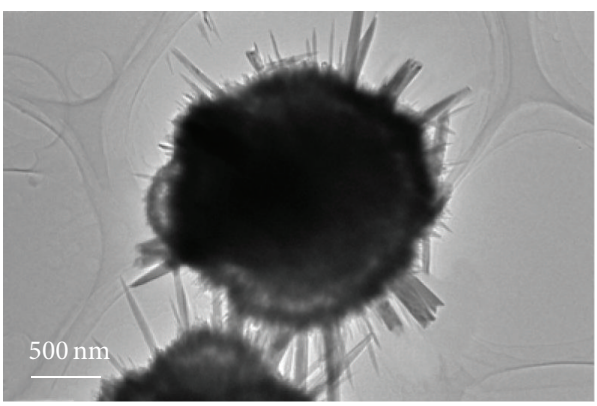

(c)

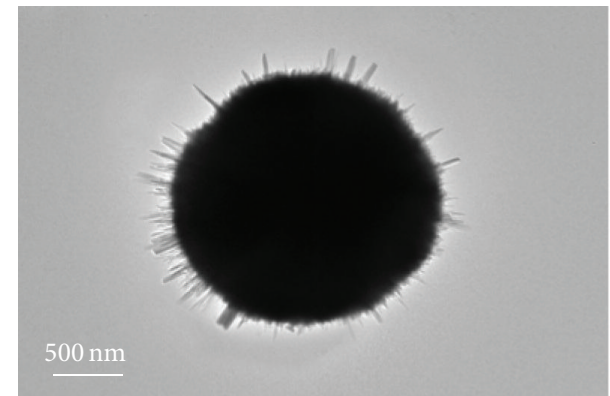

(b)

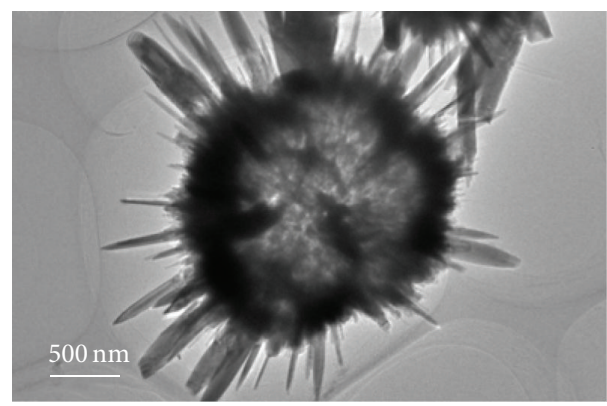

(d)

FIGURE 9: TEM images of the products obtained at different reaction time: $2 \mathrm{~h}(\mathrm{a}), 5 \mathrm{~h}(\mathrm{~b}), 8 \mathrm{~h}(\mathrm{c})$, and $12 \mathrm{~h}(\mathrm{~d})$.

In our study, CMS, as a soft template, not only facilitates the formation of well-dispersed rambutan-like $\mathrm{ZnO} H \mathrm{HHMs}$, but also serves as a diffusion boundary to restrain rapid crystal growth and prevent direct fusion among the $\mathrm{ZnO}$ spheres during the ripening process. Based on the analysis, the formation of rambutan-like $\mathrm{ZnO}$ HHMs is ascribed to CMS-assisted Ostwald ripening mechanism.

3.6. Photocatalytic Activity. In the last decade, photocatalytic oxidation process provides an effective route for the destruction of hazardous and toxic pollutants [36]. $\mathrm{RhB}$ were chosen as a model pollutant to evaluate the photocatalytic activity of rambutan-like $\mathrm{ZnO}$ HHMs.

Figure 10(a) shows the photocatalytic degradation of $\mathrm{RhB}$ in the aqueous solution as a function of exposure time in the presence of the $\mathrm{ZnO}$ catalysts under UV light irradiation. With the increase of the reaction time, the absorption peak intensity of $\mathrm{RhB}$ greatly drops down and even disappears within $90 \mathrm{~min}$ in the presence of rambutan-like $\mathrm{ZnO}$ HHMs. The time for photodegradation of $\mathrm{RhB}$ is much shorter than that of hollow $\mathrm{ZnO}$ nanospheres (150 $\mathrm{min}$ ) [37]. The apparent reaction rate constant $\left(k_{\text {app. }}\right)$ is found to be $4.15 \times 10^{-2} \mathrm{~min}^{-1}$ for rambutan-like $\mathrm{ZnO}$ HHMs (Figure $10(\mathrm{~b})$ ), while $k_{\text {app. }}$ is 


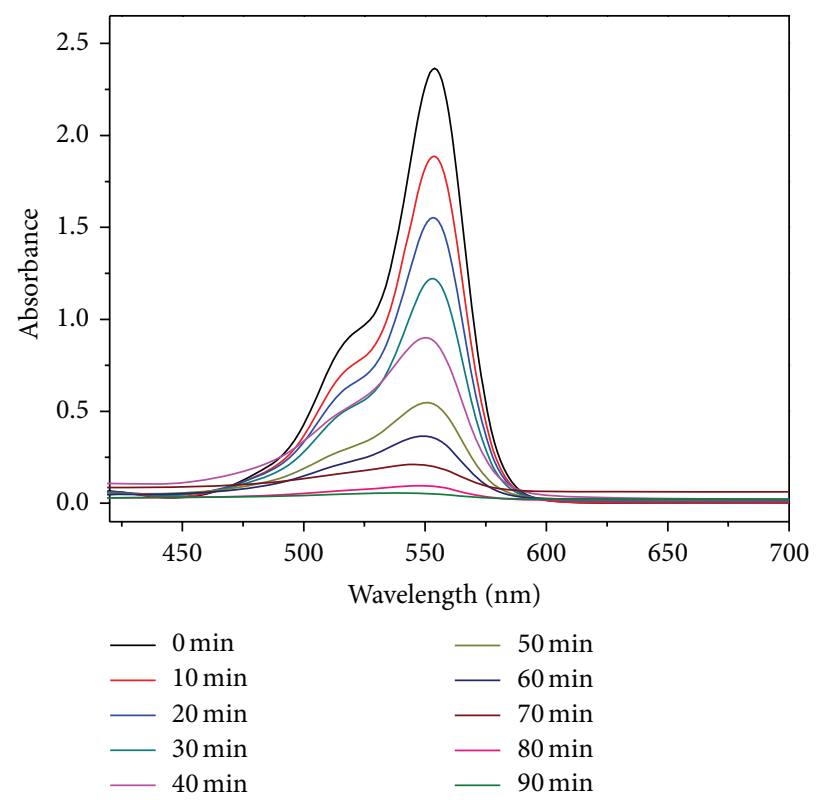

(a)

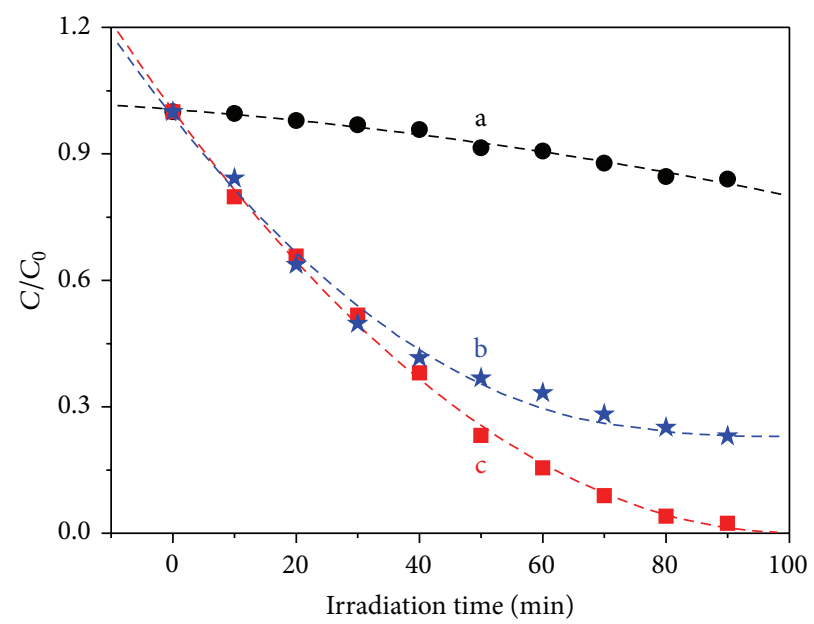

(b)

FIGURE 10: (a) UV-vis absorption spectra from the $2.5 \times 10^{-5} \mathrm{M} \mathrm{RhB}$ solution with $0.3 \mathrm{mg} \cdot \mathrm{mL}^{-1}$ hollow rambutan-like $\mathrm{ZnO} \mathrm{HHMs}$ at different time intervals and (b) $\mathrm{RhB}$ photodegradation curves of the $C / C_{0}$ versus time in the absence (curve a) and presence of commercial $\mathrm{ZnO}$ (curve b) or rambutan-like $\mathrm{ZnO}$ HHMs (curve c).

$2.12 \times 10^{-2} \mathrm{~min}^{-1}$ for the blank system (without $\mathrm{ZnO}$ ). The $k_{\text {app. }}$ of rambutan-like $\mathrm{ZnO}$ HHMs is much higher than the photocatalysis of Congo red $\left(4.15 \times 10^{-2} \mathrm{~min}^{-1}\right)$ using hollow flower-like $\mathrm{ZnO}$ structures as a catalyst [21], although the amount of the catalysts used is at the same level. After 90 min of UV irradiation, almost $100 \%$ of RhB molecules are decomposed for rambutan-like $\mathrm{ZnO}$ HHMs, unlike that of commercial $\mathrm{ZnO}$ with $23 \%$ of $\mathrm{RhB}$ molecules remaining. It indicates that the photocatalytic activity of rambutan-like $\mathrm{ZnO} \mathrm{HHMs}$ is much higher than that of commercial $\mathrm{ZnO}$. Moreover, the rambutan-like $\mathrm{ZnO} \mathrm{HHMs}$ also display highly photocatalytic stability after five times recycling (Figure S5, supporting information).

Figure S6 (supporting information) shows the photocatalytic performance when using the samples obtained at different reaction time. It is found that the photocatalytic activity increased when the morphology is more close to the structure of $\mathrm{ZnO} \mathrm{HHMs}$, owing to the enlarged surface area of the unique structures. $\mathrm{RhB}$ molecules are excited by the absorption of UV light, and electrons are injected into the conduction band of $\mathrm{ZnO}$ particles, facilitating the oxidation of $\mathrm{RhB}$ molecules [38]. These results clearly demonstrate that $\mathrm{ZnO} \mathrm{HHMs}$ have enhanced photocatalytic activity. In addition, the exposed facets of the $\mathrm{ZnO}$ structures also play an important role. The nanorods of $\mathrm{ZnO} H \mathrm{HH}$ s are growing along the $\{10 \overline{1} 1\}$ planes. The weaker coordinated $\mathrm{O}$ atoms on the surface are more likely to be saturated by $\mathrm{H}$ atoms in aqueous solution, thereby releasing more free $\mathrm{OH}$ radicals under irradiation, as supported by the previous work [39].

\section{Conclusions}

In summary, a simple and green pathway has been explored for the construction of rambutan-like $\mathrm{ZnO} \mathrm{HHMs}$ under hydrothermal conditions. CMS, as a soft template, plays an important role in the synthesis procedure. The formation of rambutan-like $\mathrm{ZnO} \mathrm{HHMs}$ was attributed to CMS-assisted Ostwald ripening process. The as-prepared $\mathrm{ZnO}$ structures were demonstrated as a good catalyst for photocatalytic degradation of RhB. This work not only provides a simple method to prepare $\mathrm{ZnO}$ hollow structures, but also sheds some light on the improvement of the photocatalytic performance by designing efficient catalysts.

\section{Conflict of Interests}

The authors declare that there is no conflict of interests regarding the publication of this paper.

\section{Acknowledgment}

This work was financially supported by the National Natural Science foundation of China (21275130 and 51178283).

\section{References}

[1] P. Baviskar, A. Ennaoui, and B. Sankapal, "Influence of processing parameters on chemically grown $\mathrm{ZnO}$ films with low cost Eosin-Y dye towards efficient dye sensitized solar cell," Solar Energy, vol. 105, pp. 445-454, 2014. 
[2] A. B. Gurav, S. S. Latthe, R. S. Vhatkar et al., "Superhydrophobic surface decorated with vertical $\mathrm{ZnO}$ nanorods modified by stearic acid," Ceramics International, vol. 40, no. 5, pp. 71517160, 2014.

[3] P. Labouchere, A. K. Chandiran, T. Moehl et al., "Passivation of $\mathrm{ZnO}$ nanowire guests and 3D inverse opal host photoanodes for dye-sensitized solar cells," Advanced Energy Materials, vol. 4, no. 12, 2014.

[4] L. Liu, K. Hong, X. Ge, D. Liu, and M. Xu, "Controllable and rapid synthesis of long $\mathrm{ZnO}$ nanowire arrays for dye-sensitized solar cells," The Journal of Physical Chemistry C, vol. 118, no. 29, pp. 15551-15555, 2014.

[5] A. Katoch, S.-W. Choi, H. W. Kim, and S. S. Kim, "Highly sensitive and selective $\mathrm{H}_{2}$ sensing by $\mathrm{ZnO}$ nanofibers and the underlying sensing mechanism," Journal of Hazardous Materials, vol. 286, no. 9, pp. 229-235, 2015.

[6] S. Hussain, T. Liu, M. Kashif et al., "Surfactant dependent growth of twinned $\mathrm{ZnO}$ nanodisks," Materials Letters, vol. 118, pp. 165-168, 2014.

[7] T. Bai, Y. Xie, C. Zhang, Y. Zhang, J. Hu, and J. Wang, "Facile fabrication of $\mathrm{ZnO}$ nanorods/ZnO nanosheet-spheres hybrid photoanode for dye-sensitized solar cells," Functional Materials Letters, vol. 8, no. 1, Article ID 1550012, 2015.

[8] P. P. Das, S. A. Agarkar, S. Mukhopadhyay, U. Manju, S. B. Ogale, and P. S. Devi, "Defects in chemically synthesized and thermally processed $\mathrm{ZnO}$ nanorods: implications for active layer properties in dye-sensitized solar cells," Inorganic Chemistry, vol. 53, no. 8, pp. 3961-3972, 2014.

[9] J. Yang, Y. Lin, Y. Meng, and Y. Lin, "Oriented $\mathrm{ZnO}$ nanotubes arrays decorated with $\mathrm{TiO} 2$ nanoparticles for dye-sensitized solar cell applications," Applied Physics A, vol. 114, no. 4, pp. 1195-1199, 2014.

[10] J.-S. Jeong, B.-H. Choe, J.-H. Lee, J.-J. Lee, and W.-Y. Choi, "ZnO-coated $\mathrm{TiO}_{2}$ nanotube arrays for a photoelectrode in dyesensitized solar cells," Journal of Electronic Materials, vol. 43, no. 2, pp. 375-380, 2014.

[11] T. A. Safeera, N. Johns, P. V. Athma, P. V. Sreenivasan, and E. I. Anila, "Synthesis and characterization of $\mathrm{ZnO}$ nanonails," AIP Conference Proceedings, vol. 1620, no. 1, pp. 572-577, 2014.

[12] L. Song, Q. Jiang, P. Du, Y. Yang, J. Xiong, and C. Cui, "Novel structure of $\mathrm{TiO}_{2}-\mathrm{ZnO}$ core shell rice grain for photoanode of dye-sensitized solar cells," Journal of Power Sources, vol. 261, no. 1, pp. 1-6, 2014.

[13] S. Zhu, L. Shan, X. Chen et al., "Hierarchical ZnO architectures consisting of nanorods and nanosheets prepared via a solution route for photovoltaic enhancement in dye-sensitized solar cells," RSC Advances, vol. 3, no. 9, pp. 2910-2916, 2013.

[14] T.-T. Miao, Y.-R. Guo, and Q.-J. Pan, “The SL-assisted synthesis of hierarchical $\mathrm{ZnO}$ nanostructures and their enhanced photocatalytic activity," Journal of Nanoparticle Research, vol. 15, no. 6, pp. 1-12, 2013.

[15] K. Wijeratne and J. Bandara, "Aspect-ratio dependent electron transport and recombination in dye-sensitized solar cells fabricated with one-dimensional $\mathrm{ZnO}$ nanostructures," Electrochimica Acta, vol. 148, no. 1, pp. 302-309, 2014.

[16] X. Zhou, W. Feng, C. Wang et al., "Porous $\mathrm{ZnO} / \mathrm{ZnCo}_{2} \mathrm{O}_{4}$ hollow spheres: synthesis, characterization, and applications in gas sensing," Journal of Materials Chemistry A, vol. 2, no. 41, pp. 17683-17690, 2014.

[17] J. Shi, Y. Liu, X. Zhou, Q. Su, J. Zhang, and G. Du, "Hierarchical $\mathrm{ZnO}$ hollow microspheres with strong violet emission and enhanced photoelectrochemical response," Materials Letters, vol. 132, no. 1, pp. 421-424, 2014.

[18] C. Ottone, K. Bejtka, A. Chiodoni et al., "Comprehensive study of the templating effect on the $\mathrm{ZnO}$ nanostructure formation within porous hard membranes," New Journal of Chemistry, vol. 38, no. 5, pp. 2058-2065, 2014.

[19] R. Selvakumar, N. Seethalakshmi, P. Thavamani, R. Naidu, and M. Megharaj, "Recent advances in the synthesis of inorganic nano/microstructures using microbial biotemplates and their applications," RSC Advances, vol. 4, no. 94, pp. 52156-52169, 2014.

[20] J. Yu and X. Yu, "Hydrothermal synthesis and photocatalytic activity of zinc oxide hollow spheres," Environmental Science \& Technology, vol. 42, no. 13, pp. 4902-4907, 2008.

[21] J.-J. Feng, Q.-C. Liao, A.-J. Wang, and J.-R. Chen, "Mannite supported hydrothermal synthesis of hollow flower-like $\mathrm{ZnO}$ structures for photocatalytic applications," CrystEngComm, vol. 13, no. 12, pp. 4202-4210, 2011.

[22] A.-J. Wang, Q.-C. Liao, J.-J. Feng, P.-P. Zhang, A.-Q. Li, and J.-J. Wang, "Apple pectin-mediated green synthesis of hollow double-caged peanut-like $\mathrm{ZnO}$ hierarchical superstructures and photocatalytic applications," CrystEngComm, vol. 14, no. 1, pp. 256-263, 2012.

[23] A. B. Djurišić, X. Y. Chen, and Y. H. Leung, "Recent progress in hydrothermal synthesis of zinc oxide nanomaterials," Recent Patents on Nanotechnology, vol. 6, no. 2, pp. 124-134, 2012.

[24] Y.-W. Cheng, H.-L. Su, W.-H. Lin, and C.-F. Lin, "Forming extremely smooth $\mathrm{ZnO}$ thin film on silicon substrates for growth of large and well-aligned $\mathrm{ZnO}$ rods with the hydrothermal method," Journal of Sol-Gel Science and Technology, vol. 70, no. 1, pp. 81-89, 2014.

[25] W. Guo, M. Fu, C. Zhai, and Z. Wang, "Hydrothermal synthesis and gas-sensing properties of ultrathin hexagonal $\mathrm{ZnO}$ nanosheets," Ceramics International, vol. 40, no. 1, pp. 22952298, 2014

[26] C. Wang, S. Ma, A. Sun et al., "Characterization of electrospun Pr-doped $\mathrm{ZnO}$ nanostructure for acetic acid sensor," Sensors and Actuators B: Chemical, vol. 193, no. 31, pp. 326-333, 2014.

[27] A. C. Janaki, E. Sailatha, and S. Gunasekaran, "Synthesis, characteristics and antimicrobial activity of $\mathrm{ZnO}$ nanoparticles," Spectrochimica Acta Part A: Molecular and Biomolecular Spectroscopy, vol. 144, no. 5, pp. 17-22, 2015.

[28] V. M. Guérin, J. Elias, T. T. Nguyen, L. Philippe, and T. Pauporté, "Ordered networks of $\mathrm{ZnO}$-nanowire hierarchical urchin-like structures for improved dye-sensitized solar cells," Physical Chemistry Chemical Physics, vol. 14, no. 37, pp. 12948-12955, 2012.

[29] J.-J. Feng, Z.-Z. Wang, Y.-F. Li, J.-R. Chen, and A.-J. Wang, "Control growth of single crystalline $\mathrm{ZnO}$ nanorod arrays and nanoflowers with enhanced photocatalytic activity," Journal of Nanoparticle Research, vol. 15, no. 4, pp. 1-12, 2013.

[30] Z. Deng, M. Chen, G. Gu, and L. Wu, "A facile method to fabricate $\mathrm{ZnO}$ hollow spheres and their photocatalytic property," The Journal of Physical Chemistry B, vol. 112, no. 1, pp. 16-22, 2008.

[31] B. Li and Y. Wang, "Facile synthesis and enhanced photocatalytic performance of flower-like $\mathrm{ZnO}$ hierarchical microstructures," The Journal of Physical Chemistry C, vol. 114, no. 2, pp. 890-896, 2010.

[32] J. Duan, X. Huang, and E. Wang, "PEG-assisted synthesis of ZnO nanotubes," Materials Letters, vol. 60, no. 15, pp. 1918-1921, 2006. 
[33] X. W. Lou, L. A. Archer, and Z. Yang, "Hollow micro-/nanostructures: synthesis and applications," Advanced Materials, vol. 20, no. 21, pp. 3987-4019, 2008.

[34] Y. F. Zhu, D. H. Fan, and W. Z. Shen, "Template-free synthesis of zinc oxide hollow microspheres in aqueous solution at low temperature," The Journal of Physical Chemistry C, vol. 111, no. 50, pp. 18629-18635, 2007.

[35] J. Li and C. Z. Hua, "Hollowing Sn-doped $\mathrm{TiO}_{2}$ nanospheres via Ostwald ripening," Journal of the American Chemical Society, vol. 129, no. 51, pp. 15839-15847, 2007.

[36] Z. Zhang, M. Zhang, J. Deng et al., "Potocatalytic oxidative degradation of organic pollutant with molecular oxygen activated by a novel biomimetic catalyst $\mathrm{ZnPz}(\mathrm{dtn}-\mathrm{COOH})_{4}$," Applied Catalysis B: Environmental, vol. 132-133, no. 27, pp. 9097, 2013.

[37] C. Zhu, B. Lu, Q. Su, E. Xie, and W. Lan, "A simple method for the preparation of hollow $\mathrm{ZnO}$ nanospheres for use as a high performance photocatalyst," Nanoscale, vol. 4, no. 10, pp. 30603064, 2012.

[38] W. Teng, X. Li, Q. Zhao, J. Zhao, and D. Zhang, "In situ capture of active species and oxidation mechanism of $\mathrm{RhB}$ and $\mathrm{MB}$ dyes over sunlight-driven $\mathrm{Ag} / \mathrm{Ag}_{3} \mathrm{PO}_{4}$ plasmonic nanocatalyst," Applied Catalysis B: Environmental, vol. 125, pp. 538-545, 2012.

[39] J. Chang and E. R. Waclawik, "Facet-controlled self-assembly of $\mathrm{ZnO}$ nanocrystals by non-hydrolytic aminolysis and their photodegradation activities," CrystEngComm, vol. 14, no. 11, pp. 4041-4048, 2012. 

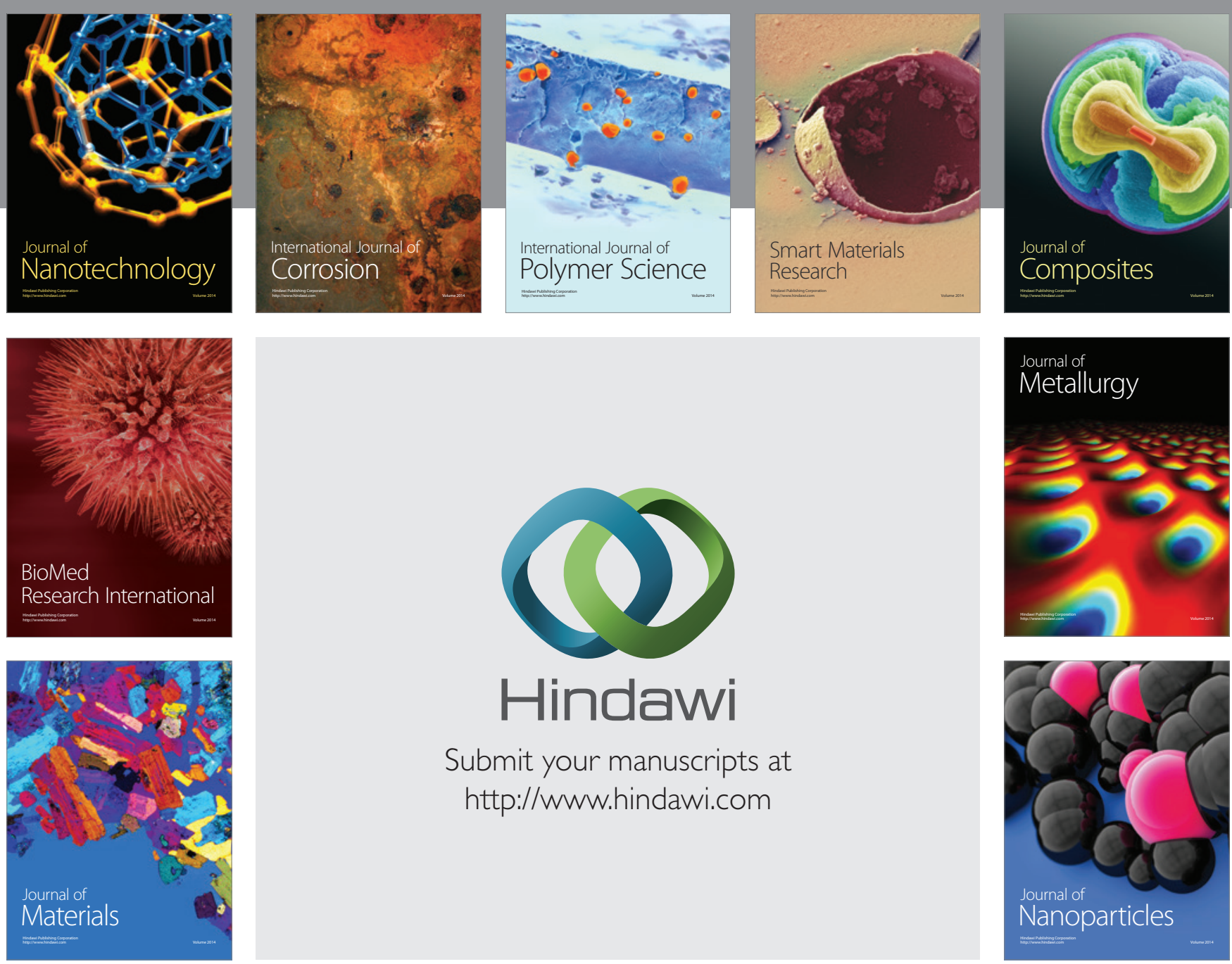

Submit your manuscripts at http://www.hindawi.com
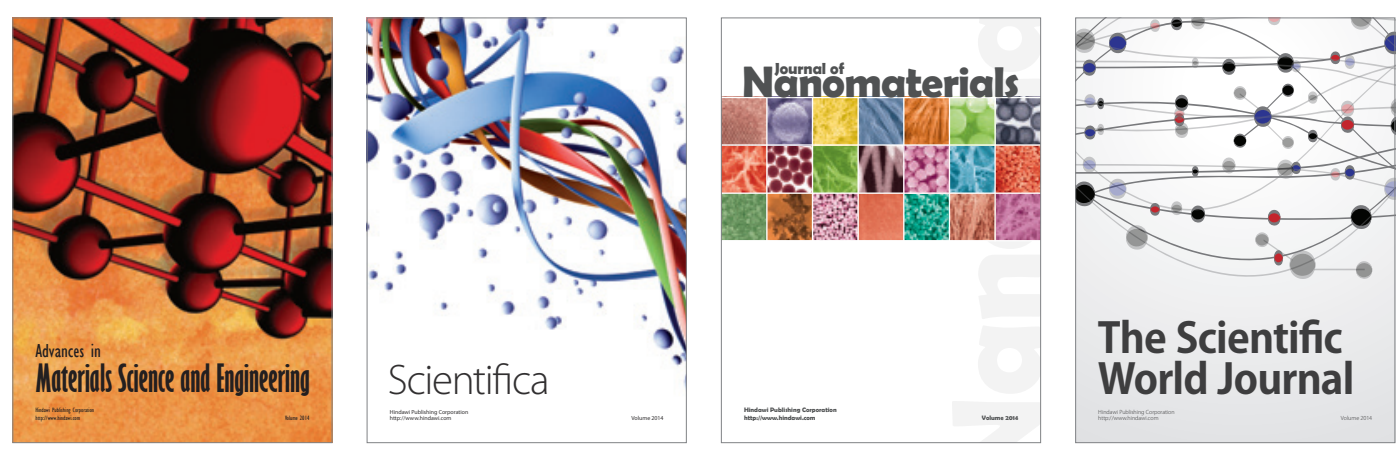

\section{The Scientific World Journal}
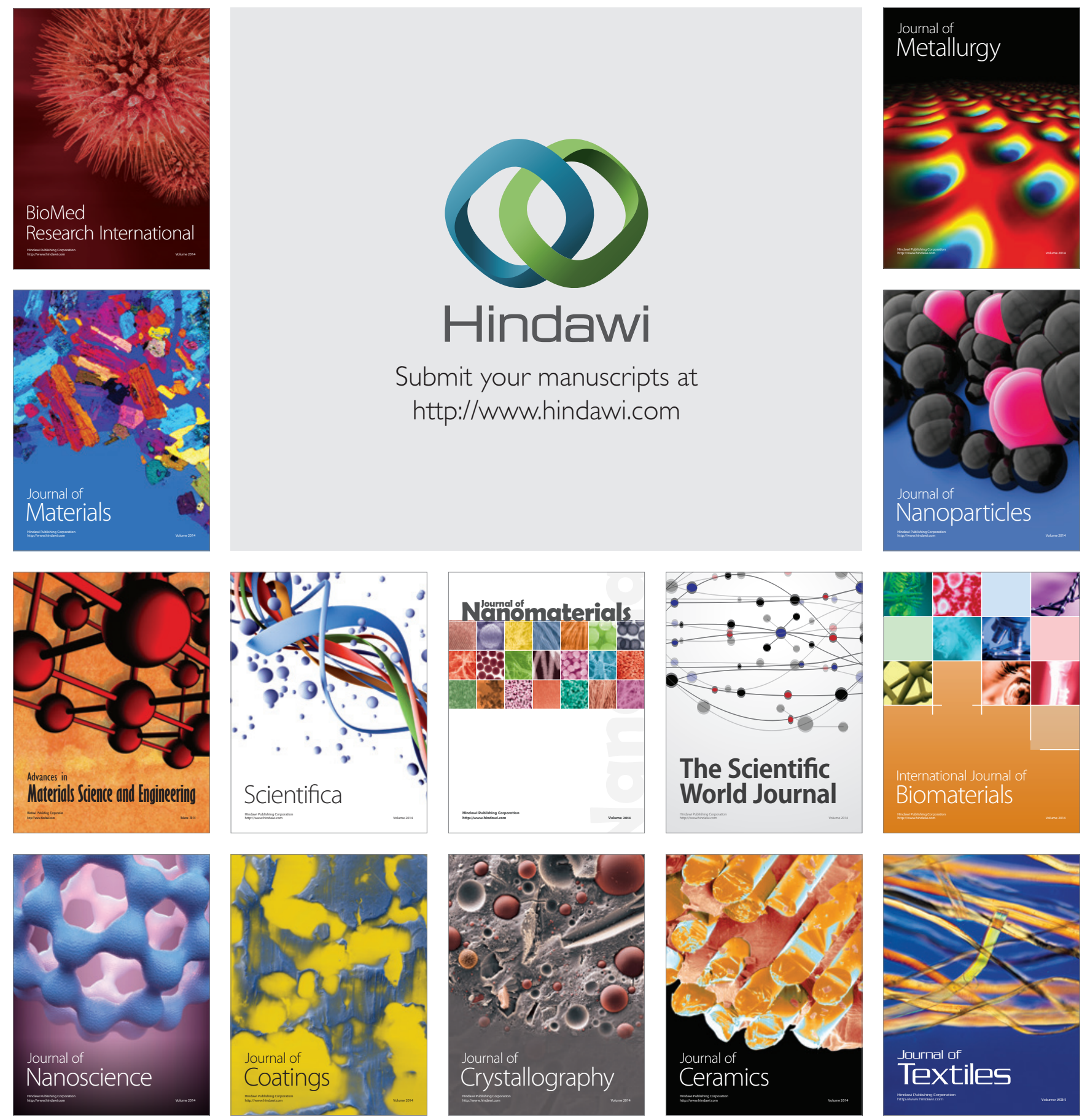